\title{
Left ventricular assist devices decrease fixed pulmonary hypertension in cardiac transplant candidates
}

Daniel Zimpfer, MD, ${ }^{\text {a }}$ Philipp Zrunek, MS, ${ }^{\text {b }}$ Wilfried Roethy, MD, ${ }^{a}$ Martin Czerny, MD, ${ }^{a}$ Heinz Schima, PhD, Leopold Huber, PhD, ${ }^{\mathrm{b}}$ Michael Grimm, MD, ${ }^{a}$ Angela Rajek, $\mathrm{MD}^{\mathrm{c}}$ Ernst Wolner, MD, PhD, ${ }^{\mathrm{a}}$ and Georg Wieselthaler, $\mathrm{MD}^{\mathrm{a}}$

From the Departments of Cardiothoracic Surgery, ${ }^{\mathrm{a}}$ Biomedical Engineering, ${ }^{\mathrm{b}}$ and Cardiovascular Anesthesiology, ${ }^{\mathrm{c}}$ Medical University of Vienna, Wahringer Guertel, Vienna, Austria.

Received for publication Jan 21, 2006; revisions received Aug 3, 2006; accepted for publication Aug 10, 2006.

Address for reprints: Daniel Zimfer, MD, Department of Cardiothoracic Surgery, Medical University Vienna, Waehringer Guertel, A-1090 Vienna, Austria (E-mail: daniel.zimpfer@meduniwien.ac.at).

J Thorac Cardiovasc Surg 2007;133:689-95

$0022-5223 / \$ 32.00$

Copyright (C) 2007 by The American Association for Thoracic Surgery

doi:10.1016/j.jtcvs.2006.08.104
Objective: Fixed pulmonary hypertension is a contraindication for cardiac transplantation because of the increased risk of donor heart failure. We sought to determine whether left ventricular assist devices improve fixed pulmonary hypertension in cardiac transplant candidates to enable safe cardiac transplantation.

Methods: Thirty-five consecutive cardiac transplant candidates (age $56 \pm 6$ years, $88.5 \%$ were men) with fixed pulmonary hypertension $(5.1 \pm 2.6$ Wood units) resistant to medical treatment received a left ventricular assist device as a bridge to transplantation. Three left ventricular assist device systems were used (pulsatile blood flow: Novacor [World Heart Inc, Oakland, Calif] $\mathrm{n}=8$; continuous blood flow: MicroMed DeBakey [MicroMed Technology Inc, Houston, Tex] $\mathrm{n}=24$, DuraHeart [Terumo Heart Inc, Ann Arbor, Mich] n = 3). Right-sided heart catheter data were obtained before left ventricular assist device implantation at 3-day and 6-week follow-ups. Clinical data and complications were recorded.

Results: Before left ventricular assist device implantation, the pulmonary vascular resistance was $5.1 \pm 2.8$ Wood units. Values were comparable in patients receiving pulsatile $(5.1 \pm 3.4$ Wood units) or continuous blood flow left ventricular assist devices $(5.1 \pm 2.7$ Wood units, $P=.976)$. Left ventricular assist device implantation decreased pulmonary vascular resistance at 3-day $(2.9 \pm 1.3$ Wood units, $P<.0001)$ and 6-week $(2.0 \pm 0.8$ Wood units, $P<.0001)$ follow-ups compared with before implantation. This effect was independent of the type of left ventricular assist device system used (3-day follow-up: pulsatile flow: $3.2 \pm 1.3$ Wood units vs continuous flow: $2.7 \pm 1.2$ Wood units; $P=.310$ and 6-week follow-up: pulsatile flow: $1.9 \pm 0.9$ Wood units vs continuous flow: $2.1 \pm 0.8$ Wood units; $P=.905$ ). Twenty-four patients had successful bridges to transplantation $(69 \%$, mean time on left ventricular assist device $210 \pm 83$ days), and 11 patients died before transplantation (31\%, mean time on left ventricular assist device $67 \pm 30$ days). The 1-year survival after transplantation was $95 \%$.

Conclusion: Left ventricular assist devices decrease fixed pulmonary hypertension in cardiac transplant candidates and allow patients to overcome a contraindication for cardiac transplantation. Therefore, left ventricular assist devices should be considered in all cardiac transplant candidates with fixed pulmonary hypertension.

$\mathrm{T}$ The prevalence of congestive heart failure is continuously increasing in the Western world. ${ }^{1}$ Despite continuous advances of medical therapy for congestive heart failure, cardiac transplantation is the most effective treatment for patients with end-stage heart failure. ${ }^{2}$

Pulmonary hypertension $(\mathrm{PH})$ is a risk factor for early and late death after cardiac transplantation. The reason for this is the unacceptably high risk of acute donor right-sided heart failure immediately after implantation. ${ }^{3-7}$ There is consensus that the risk of death after cardiac transplantation is increased in patients with pulmonary 


$$
\begin{aligned}
& \text { Abbreviations and Acronyms } \\
& \begin{aligned}
\text { LVAD } & =\text { left ventricular assist device } \\
\text { PG } & =\text { prostaglandin } \\
\text { PH } & =\text { pulmonary hypertension } \\
\text { PVR } & =\text { pulmonary vascular resistance } \\
\mathrm{WU} & =\text { Wood units }
\end{aligned}
\end{aligned}
$$

vascular resistance (PVR) greater than 2.5 Wood units (WU), if PVR cannot be decreased by pharmacologic interventions (fixed $\mathrm{PH}$ ). ${ }^{8,9}$ Various pharmacologic agents have been evaluated for their ability to decrease PVR in these patients. ${ }^{10}$ Pharmacologic agents tested include sodium nitroprusside, inhaled nitric oxide, phosphodiesterase inhibitors, urapidil, prostaglandins (PGE1 and PGI1), and levosimendan. ${ }^{10-14}$ However, even by combining these pharmacologic agents, $\mathrm{PH}$ cannot be significantly decreased in many of these patients. No safe and efficient treatment can be offered to those patients with end-stage heart failure and fixed severe PH today. Left ventricular assist devices (LVADs) have been reported to reduce $\mathrm{PH}$ in patients with terminal heart failure. We are the first to study this topic in a prospective fashion and to compare pulsatile and continuous flow LVADS. ${ }^{15-17}$

In this prospective study we report on our experience with the treatment strategy of improving fixed PH in cardiac transplant candidates by means of LVAD implantation and subsequent orthotopic cardiac transplantation.

\section{Materials and Methods \\ Patients}

During the study period, 242 cardiac transplant candidates were admitted to our hospital. Of those, 72 patients received an LVAD. Indication for LVAD implantation was terminal heart failure without fixed $\mathrm{PH}$ in 36 patients (50\%), destination therapy in 1 patient (1\%), and terminal heart failure with fixed PH (>3.5 WU) in 35 patients $(49 \%)$. The 35 consecutive patients with terminal heart failure and fixed $\mathrm{PH}$ entered this prospective study. To qualify, all patients had to fulfill institutional inclusion criteria for terminal heart failure and had to have fixed $\mathrm{PH}$ unresponsive to maximum medical treatment. With the exception of fixed $\mathrm{PH}$, patients had to be suitable for cardiac transplantation. The study was approved by the institutional review board, and all patients gave their written and informed consent before LVAD implantation and subsequent cardiac transplantation.

The duration of support, survival, incidence of neurologic complications, device malfunctions, and infections were monitored. Infections were defined as the presence of a positive blood culture along with a leukocytosis.

\section{Devices, Implant Procedure, and Anticoagulation}

Three different systems of LVADs were used in the present study. The technical details and implantation procedures of the
MicroMed DeBakey (MicroMed Technology Inc, Houston, Tex), DuraHeart (Terumo Heart Inc, Ann Arbor, Mich) (continuous blood flow), and Novacor LVADs (World Heart Inc, Oakland, Calif) (pulsatile blood flow) have been described. ${ }^{18-20}$

Anticoagulation protocol was identical in all patients. During extracorporal circulation and implantation of the pump, patients received intravenous heparin $(300 \mathrm{U} / \mathrm{kg}$ body weight), and the heart-lung machine was primed with 1,000,000 IU aprotinin. After discontinuation of extracorporal circulation, heparin was reversed with an appropriate dose of protamine. Intravenous heparin was instituted 6 hours after surgery to achieve activated partial thromboplastin target times of 50 to 60 seconds. Platelet anti-aggregation therapy with $150 \mathrm{mg}$ per day of aspirin and $225 \mathrm{mg}$ per day of dipyridamole was started after removal of all chest drains. Administration of heparin was stopped when anticoagulation with coumarin reached target levels of 2.5 to 3.5 international normalized ratio.

\section{Measurement of Pulmonary Hypertension}

Right-sided heart catheterization was performed according to the guidelines published by the American College of Cardiology/ American Heart Association using a Swan-Ganz thermodilution catheter. Right-sided heart catheterization was performed before LVAD implantation and 3 days and 6 weeks after LVAD implantation. $^{21}$ The PH variables assessed included PVR (Wood units), systolic pulmonary artery pressure (millimeters of mercury), mean pulmonary artery pressure (millimeters of mercury), pulmonary capillary wedge pressure (millimeters of mercury), and cardiac output (liters per minute). Cardiac output was measured with the Fick method.

\section{Testing for Reversibility of Pulmonary Hypertension}

$\mathrm{PH}$ was defined as PVR greater than 3.5 WU. Reversibility of PH was assessed by nitroglycerin, prostaglandin (PGI2), nitric oxide, and levosimendan (only available in the last 10 patients). Nitroglycerin was applied intravenously at increasing doses of 2 to $6 \mathrm{mg}$ per hour with dose increments every 10 minutes. PGI2 was given intravenously at increasing doses of 10 to $200 \mathrm{ng} / \mathrm{kg} / \mathrm{min}$ with dose increments every 5 minutes. Nitric oxide was administered in doses of 40, 60, and $80 \mathrm{ppm}$ through a tight-fitting facemask. In the last 10 patients, levosimendan was additionally used for testing for reversibility of $\mathrm{PH}$. If $\mathrm{PH}$ was not reversible with this treatment, it was considered as fixed. All of the mentioned substances were tested in all patients (Figure 1).

\section{Statistical Analysis}

Data are presented as frequency distributions and percentages. Values of continuous variables are expressed as mean \pm standard deviation. Continuous variables were compared using analysis of variance (Bonferroni). Categoric variables were compared by means of the chi-square or Fisher exact test as appropriate. Kaplan-Meier analysis was used to calculate long-term survival along with a $\log$-rank $P$ value when comparing groups. The study was analyzed with the Statistical Package for the Social Sciences 11.5 (SPSS Inc, Chicago, Ill). 


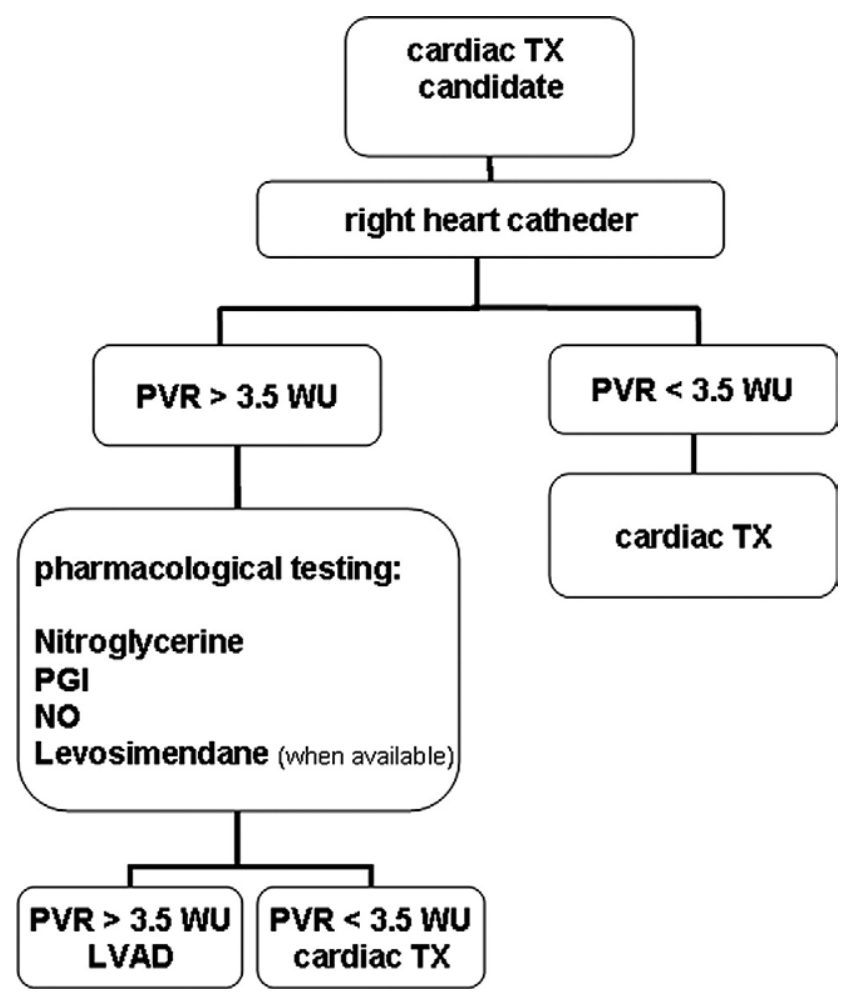

Figure 1. Pharmacologic testing: decision-making tree. $T X$, Transplant; PVR, pulmonary vascular resistance; $W U$, Wood units; $P G$, prostaglandin; NO, nitric oxide; LVAD, left ventricular assist device.

\section{Results \\ Demographics}

The characteristics of LVAD recipients are shown in Table 1. The mean overall age was 56.6 years (88.5\% were male). All patients were in New York Heart Association class IV and had fixed PH (PVR 5.1 $\pm 2.8 \mathrm{WU}$ ) before LVAD implantation. Idiopathic cardiomyopathy was the most common cause of heart failure present in 23 patients $(65.5 \%)$, and ischemic cardiomyopathy was present in 12 patients $(34.5 \%)$. Recipients of pulsatile and continuous flow LVAD were comparable with regard to patient characteristics (Table 1). Overall mechanical support time was $202 \pm 169$ days (range, 35-700 days).

\section{Survival}

Twenty-four patients (69\%) had successful bridges to transplantation (bridge to transplant time $210 \pm 83$ days), and 11 patients $(31 \%)$ died during LVAD support (survival time $67 \pm 30$ days). One patient (5\%) died after cardiac transplantation. We found no difference in bridge to transplant success between patients treated with pulsatile $(62.5 \%)$ or continuous flow $(71.1 \%)$ LVAD $(P=$ .147). One-year survival after cardiac transplantation was
95\%. The mean follow-up after cardiac transplantation was $25 \pm 17$ months. Overall survival is displayed in Figure 2.

\section{Right-sided Heart Catheterization}

Before LVAD implantation, PVR was $5.1 \pm 2.8 \mathrm{WU}$. Values were comparable in patients receiving pulsatile $(5.1 \pm 3.4 \mathrm{WU})$ and continuous blood flow LVADs (5.1 \pm 2.7 WU, $P=.976)$. LVAD implantation decreased PVR at 3-day $(2.9 \pm 1.3 \mathrm{WU}, P<.0001)$ and 6-week follow-ups $(2.0 \pm 0.8 \mathrm{WU}, P<.0001)$ compared with before implantation. This effect was independent of the type of LVAD system used (3-day follow-up: pulsatile flow $3.2 \pm 1.3 \mathrm{WU}$ vs continuous flow $2.7 \pm 1.2 \mathrm{WU}, P=.310$; 6-week follow-up: pulsatile flow $1.9 \pm 0.9 \mathrm{WU}$ vs continuous flow $2.1 \pm 0.8 \mathrm{WU}, P=.905)$. Detailed hemodynamic data are shown in Table 2.

\section{Complications and Causes of Death}

The incidence and nature of complications and the causes of death are shown in Table 3. None of the patients required mechanical right-sided heart support after LVAD implantation. A total of $51.3 \%$ of patients experienced a complication while on LVAD support. Cerebrovascular events occurred in $31 \%$ of patients, and infections occurred in $25.7 \%$ of patients. We found no difference in the incidence and nature of complications between patients treated with pulsatile and continuous blood flow devices (Table 3). Cerebrovascular events were the most common cause of death present in $45.4 \%$ of patients, followed by multiorgan failure $(36.3 \%)$ and infections $(18.3 \%)$. We found no difference in the incidence and nature of complications between patients treated with pulsatile and continuous blood flow devices (Table 3).

\section{Discussion}

Severe fixed PH is a contraindication for cardiac transplantation because of an increased risk of postoperative donor heart failure. LVADs decrease fixed $\mathrm{PH}$ in cardiac transplant candidates and enable them to undergo orthotopic cardiac transplantation.

Pulmonary vascular hypertension is a common complication of severe long-standing heart failure. Approximately $72 \%$ of patients with terminal heart failure who are eligible for cardiac transplantation have $\mathrm{PH}^{22}$ The pathophysiology behind $\mathrm{PH}$ in patients with terminal heart failure is the result of a multifactorial process mainly relating to left ventricular failure. ${ }^{23}$ Left atrial hypertension resulting from left ventricular failure translates into increased postcapillary pressure in the pulmonary circulation. ${ }^{23}$ This enhances pulmonary endothelial dysfunction with decreased availability of nitric oxide and prostacyclin and increased production of thromboxane A2 and endothelin-1. ${ }^{23}$ The activity of serine 
TABLE 1. Patient characteristics and heart failure therapy

\begin{tabular}{|c|c|c|c|c|}
\hline Variable & All patients & Continuous flow* & Pulsatile flowt & $P$ value $\neq$ \\
\hline $\mathrm{n}$ & 35 & 27 & 8 & \\
\hline Age (y) & $56.6 \pm 7$ & $54.2 \pm 5$ & $58.2 \pm 8$ & .853 \\
\hline Male $(\%)$ & 88.5 & 92.5 & 87.5 & .345 \\
\hline Disease (CAD/ICM, \%) & $34.5 / 65.5$ & $37.3 / 62.7$ & $36.6 / 63.4$ & .679 \\
\hline Weight $(\mathrm{kg})$ & $80.4 \pm 12.2$ & $78.6 \pm 13.5$ & $82.3 \pm 14.1$ & .872 \\
\hline Height $(\mathrm{cm})$ & $170 \pm 12$ & $172 \pm 9$ & $171 \pm 6$ & .941 \\
\hline Ejection fraction (\%) & $18.2 \pm 6.3$ & $17.9 \pm 7.3$ & $18.3 \pm 8.2$ & .762 \\
\hline COPD $(\%)$ & 12.5 & 11.1 & 12.5 & .928 \\
\hline Renal failure $(\%)$ & 28.1 & 22.2 & 37.5 & .675 \\
\hline Diabetes $(\%)$ & 22.8 & 22.2 & 25.5 & .314 \\
\hline Heart rate (beats/min) & $95 \pm 7$ & $93 \pm 8$ & $96 \pm 6$ & .345 \\
\hline $\mathrm{AOP}(\mathrm{mm} \mathrm{Hg})$ & $90 / 60$ & $93 / 58$ & $88 / 62$ & .476 \\
\hline Heart failure $(y)$ & 5.3 & 5.5 & 5.1 & .674 \\
\hline Diuretics (\%) & 100 & 100 & 100 & 1.000 \\
\hline Beta-blockers (\%) & 94.5 & 92.3 & 87.5 & .429 \\
\hline ACE inhibitor (\%) & 100 & 100 & 100 & 1.000 \\
\hline Inotropic support (\%) & 0 & 0 & 0 & 1.000 \\
\hline
\end{tabular}

$C A D$, Coronary artery disease; ICM, idiopathic cardiomyopathy; COPD, chronic obstructive pulmonary disease; $A O P$, aortic pressure (only mean values given); $A C E$, angiotensin-converting enzyme. Renal failure: defined as creatinine $>2.0 \mathrm{mg} / \mathrm{dL}(177 \mu \mathrm{mol} / \mathrm{L})$. Heart failure (y): duration of heart failure. *Patients treated with continuous flow LVADs. $†$ Patients treated with pulsatile flow LVADs. $\ddagger P$ value: continuous flow LVADs versus pulsatile flow LVADs.

elastase is up-regulated in the subendothelium causing glycoprotein deposition and smooth muscle cell hypertrophy and hyperplasia. ${ }^{24}$ Intermittent hypoxia stimulates vasoconstriction in the pulmonary vascular tree. Changes in the expression of von Willebrand factor result in the development of platelet fibrin microthrombi. ${ }^{25}$ In addition, this process is associated with smooth muscle cell hypertrophy and hyperplasia. ${ }^{23}$ Depending on the duration of these processes, remodeling of the pulmonary vascular tree takes place.

Fixed PH is considered to be present when elevated PVR cannot be significantly decreased $(>20 \%)$ by pharmacologic interventions. ${ }^{6,26}$ Although there is no international consensus, most transplant centers will not offer cardiac transplantation in patients with PVR greater than 3 to $4 \mathrm{WU}$ for the following reasons. In the case of cardiac transplantation, the relatively thin-walled right ventricle of the organ donor does not function adequately in the presence of abnormally elevated PVR. This carries the high risk of distension of the donor right ventricle, resulting in right ventricular failure. In this case, neither high doses of inotropes nor mechanical support of the right ventricle results in a satisfying outcome. ${ }^{26-29}$ Posttransplant survival in patients with fixed $\mathrm{PH}$ is significantly worse compared with patients with normal PVR in both short and long-term follow-ups. ${ }^{3-7,29}$

In the present study, LVADs decreased fixed $\mathrm{PH}$ during a 6-week period of support. PH in terminal heart failure, at least in part, is the consequence of elevated left atrial filling pressures resulting from impaired left ventricular systolic function. Therefore, it might be speculated that LVADs reverse this process by continuously unloading the left ventricle. It remains to be studied whether LVAD support results in a reverse-remodeling of the pulmonary vascular tree. Pulsatile and continuous blood flow LVADs equally decreased PH during a 6-week period of support. It was previously emphasized that left ventricular unloading is more efficiently done by continuous blood flow devices. ${ }^{30}$ This was based on the theoretic consideration that continuous blood flow devices unload the left ventricle during the

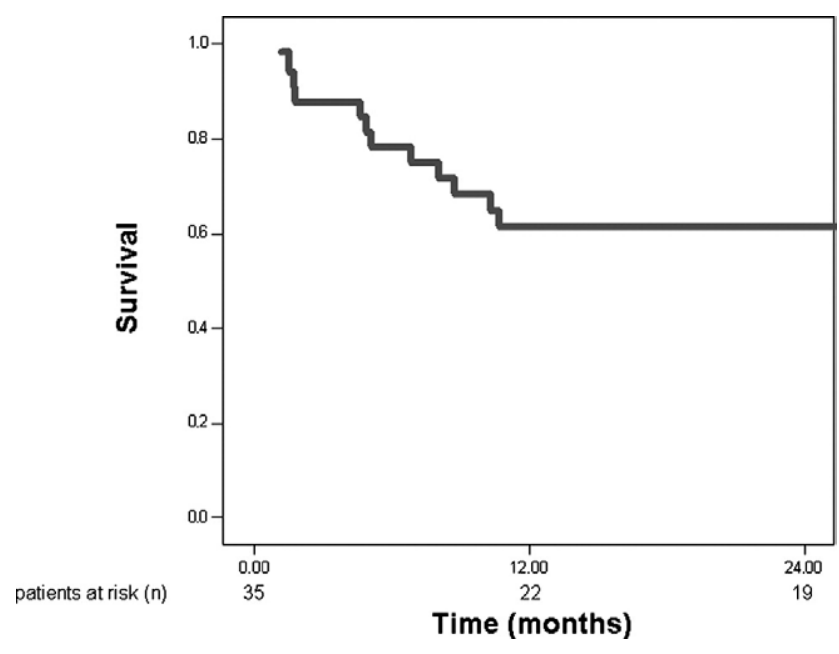

Figure 2. Kaplan-Meier curve displaying overall survival after LVAD implantation. 
TABLE 2. Data from right-sided heart catheterization

\begin{tabular}{|c|c|c|c|c|c|}
\hline Variable & All patients & $P$ value* & Continuous flowt & Pulsatile flow‡ & $P$ value§ \\
\hline$n$ & 35 & & 27 & 8 & \\
\hline \multicolumn{6}{|l|}{ PVR } \\
\hline Baseline & $5.1 \pm 2.6$ & - & $5.3 \pm 2.7$ & $5.1 \pm 3.5$ & .976 \\
\hline 3-d FUP & $2.9 \pm 1.3$ & $<.0001$ & $2.7 \pm 1.2$ & $3.2 \pm 1.3$ & .310 \\
\hline 6-wk FUP & $2.0 \pm 0.8$ & $<.0001$ & $2.1 \pm 0.8$ & $1.9 \pm 0.9$ & .905 \\
\hline After testing & $4.5 \pm 2.1$ & - & - & - & - \\
\hline \multicolumn{6}{|l|}{ PAsyst } \\
\hline Baseline & $63.2 \pm 9.3$ & - & $65.2 \pm 13.0$ & $65.3 \pm 10$ & .976 \\
\hline 3-d FUP & $39.6 \pm 10.6$ & $<.0001$ & $37.6 \pm 9.4$ & $43.4 \pm 12.5$ & .175 \\
\hline 6-wk FUP & $26.7 \pm 3.6$ & $<.0001$ & $29.6 \pm 6.5$ & $28.1 \pm 7.5$ & .236 \\
\hline After testing & $36 \pm 10.2$ & - & - & - & - \\
\hline \multicolumn{6}{|l|}{ PAmean } \\
\hline Baseline & $44.0 \pm 6.2$ & - & $45.5 \pm 6.8$ & $43.0 \pm 8.4$ & .397 \\
\hline 3-d FUP & $28.6 \pm 7.3$ & $<.0001$ & $28.1 \pm 7.5$ & $29.6 \pm 6.5$ & .604 \\
\hline 6-wk FUP & $18.4 \pm 4.3$ & $<.0001$ & $19.0 \pm 4.2$ & $17.8 \pm 5.1$ & .571 \\
\hline After testing & $30.2 \pm 6.8$ & - & - & - & - \\
\hline \multicolumn{6}{|l|}{ PCWP } \\
\hline Baseline & $28.1 \pm 6.0$ & - & $29.0 \pm 5.7$ & $27.1 \pm 7.0$ & .439 \\
\hline 3-d FUP & $12.0 \pm 5.7$ & $<.0001$ & $11.9 \pm 4.4$ & $13.0 \pm 8.3$ & .641 \\
\hline 6-wk FUP & $10.0 \pm 3.6$ & $<.0001$ & $10.1 \pm 13.7$ & $9.1 \pm 3.7$ & .572 \\
\hline After testing & $15.8 \pm 1.9$ & - & - & - & - \\
\hline \multicolumn{6}{|l|}{$\mathrm{CO}$} \\
\hline Baseline & $3.1 \pm 0.8$ & - & $3.0 \pm 0.6$ & $2.6 \pm 0.7$ & .601 \\
\hline 3-y FUP & $5.7 \pm 0.7$ & $<.0001$ & $6.2 \pm 1.1$ & $5.1 \pm 0.8$ & .375 \\
\hline 6-wk FUP & $4.0 \pm 0.9$ & .002 & $4.2 \pm 0.8$ & $4.6 \pm 0.4$ & .453 \\
\hline After testing & $3.2 \pm 7$ & - & - & - & - \\
\hline
\end{tabular}

PVR, Pulmonary vascular resistance (WU); FUP, follow-up; PAsyst, systolic pulmonary artery pressure (mm Hg); PAmean, mean pulmonary artery pressure $(\mathrm{mm} \mathrm{Hg}) ; P C W P$, pulmonary capillary wedge pressure $(\mathrm{mm} \mathrm{Hg}) ; C 0$, cardiac output $\left(\mathrm{Ixmin}{ }^{-1}\right) . * P$ value: compared with before LVAD implantation. $†$ Patients treated with continuous flow LVADs. $\$$ Patients treated with pulsatile flow LVADs. $§ P$ value: continuous flow LVADs versus pulsatile flow LVADs. Baseline: hemodynamic data immediately before LVAD implantation. After testing: hemodynamic data after pharmacologic testing.

whole cardiac circle. On the basis of this finding, the decision for the type of LVAD in cardiac transplant candidates with fixed PH should depend only on the patient's demands. Especially in large patients, the flow provided by continuous flow LVADs may be too low to increase exercise tolerance and enable recovery of the patient. ${ }^{31}$

Compared with the high risk of donor heart failure in patients with fixed $\mathrm{PH}$ and orthotopic cardiac transplantation, the combined approach of LVAD support and subsequent cardiac transplantation seems promising. Successful bridging rates ranging from $65 \%$ to $70 \%$ have been reported in patients without $\mathrm{PH}^{32}$ We successfully bridged $69 \%$ of patients to safe cardiac transplantation. Posttransplant survivals at 30-day (95\%) and 12-month (95\%) follow-ups were comparable to those reported in patients without $\mathrm{PH}$ at the time of cardiac transplantation. ${ }^{33}$ Because of these results, all cardiac transplant candidates with a PVR greater than 3.5 WU (after testing for reversibility) receive an LVAD before cardiac transplantation at our center. Alternative approaches to orthotopic cardiac transplantation, such as heterotopic cardiac transplanta- tion and right ventricle-sparing transplant techniques, have been recommended in the past in patients with severe $\mathrm{PH}^{34,35}$ In these select cases, the donor heart acts as a biological assist device to the native left ventricle or both ventricles. Survivals reported at 12 -month follow-ups range between $83 \%$ and $59 \% .^{34,35}$ The major limitations of heterotopic transplantation are the availability of a suitable donor, technical difficulties during implantation, and, in particular, late interactions of donor and recipient heart. ${ }^{36}$ Survivals with these alternative approaches are significantly lower compared with LVAD implantation and subsequent orthotopic cardiac transplantation. The presented algorithm significantly reduces the incidence of right-sided heart failure after cardiac transplantation to less than $1 \%$ and is associated with good posttransplant survival.

Nevertheless, patient morbidity while on LVAD support still remains a major concern, because $51 \%$ of all patients exhibited a severe adverse event. Most common were neurologic events, which also significantly contributed to patient mortality on LVAD support. Other complications included infections and bleeding. No device-related complications were 
TABLE 3. Complications and causes of death

\begin{tabular}{lcccc}
\hline Variable & $\begin{array}{c}\text { All } \\
\text { patients }\end{array}$ & $\begin{array}{c}\text { Continuous } \\
\text { flow* }\end{array}$ & $\begin{array}{c}\text { Pulsatile } \\
\text { flowt }\end{array}$ & $\begin{array}{c}\boldsymbol{P} \\
\text { valuef }\end{array}$ \\
\hline Incidence of complications & 51.3 & 51.8 & 50.0 & .370 \\
Reoperation for bleeding & 17.1 & 18.1 & 12.5 & .261 \\
CVA & 31.4 & 33.4 & 25.0 & .297 \\
$\begin{array}{l}\text { Infection } \\
\text { Causes of death }\end{array}$ & 25.7 & 25.9 & 25.0 & .284 \\
$\quad$ No. died while on LVAD & 11 & 8 & 3 & .147 \\
$\quad \begin{array}{l}\text { Multiorgan failure } \\
\quad \text { (n, \%) }\end{array}$ & 36.3 & 37.5 & 33.3 & .672 \\
$\quad$ CVA & & & & \\
$\quad$ Infection & 45.4 & 50.0 & 33.3 & .542 \\
\end{tabular}

CVA, Cerebrovascular accident; $L V A D$, left ventricular assist device. $* \mathrm{~Pa}$ tients treated with continuous flow LVADs. $†$ Patients treated with pulsatile flow LVADs. $\ddagger P$ value: continuous flow LVADs versus pulsatile flow LVADs.

observed. In our series the incidence of adverse events compares with that reported by others. ${ }^{37,38}$ There was no difference in adverse events between pulsatile and continuous flow LVADs. Continuous research, improvement of devices, and careful patient selection are crucial to reduce LVAD-associated complications.

\section{Conclusions}

The primary limitation of the present study is the nonrandomized design. The reason for this design is because fixed $\mathrm{PH}$ is a contraindication for cardiac orthotopic transplantation. Therefore, comparing cardiac transplantation with and without prior LVAD implantation would be ethically questionable.

LVADs decrease fixed $\mathrm{PH}$ in cardiac transplant candidates and allow them to overcome fixed $\mathrm{PH}$ as a contraindication for cardiac transplantation. Therefore, LVADs should be considered in all cardiac transplant candidates with fixed $\mathrm{PH}$.

We thank Daniela Dunkler, MSc, from the Institute of Medical Biometry, Medical University of Vienna, for assistance with the statistical analysis.

\section{References}

1. Smith ER. Heart failure-are we making progress? Can J Cardiol. 2002;18:1124-5.

2. Meyer B, Moertl D, Huelsmann M, Pacher R, Berger R. In the long term heart transplantation provides additional benefit in transplant candidates with uptitrated ACE-inhibitor- and $\beta$-blocker-therapy. J Heart Lung Transplant. 2005;24:S69.

3. Chen JM, Levin HR, Michler RE, Prusmack CJ, Rose EA, Aaronson $\mathrm{KD}$. Reevaluating the significance of pulmonary hypertension before cardiac transplantation: determination of optimal thresholds and quantification of the effect of reversibility on perioperative mortality. J Thorac Cardiovasc Surg. 1997;114:627-34.

4. Costard-Jackle A, Fowler MB. Influence of preoperative pulmonary artery pressure on mortality after heart transplantation: testing of potential reversibility of pulmonary hypertension with nitroprusside is useful in defining a high risk group. J Am Coll Cardiol. 1992;19:48-54.
5. Espinoza C, Manito N, Castells E, Roca J, Rodriguez R, Octavio de Toledo MC, et al. Pretransplant risk factors of early mortality after orthotopic heart transplantation. Transplant Proc. 1999;31:2507-8.

6. Murali S, Uretsky BF, Armitage JM, Tokarczyk TR, Betschart AR, Kormos RL, et al. Utility of prostaglandin E1 in the pretransplantation evaluation of heart failure patients with significant pulmonary hypertension. J Heart Lung Transplant. 1992;11:716-23.

7. Murali S, Kormos RL, Uretsky BF, Schechter D, Reddy PS, Denys $\mathrm{BG}$, et al. Preoperative pulmonary hemodynamics and early mortality after orthotopic cardiac transplantation: the Pittsburgh experience. Am Heart J. 1993;126:896-904.

8. Delgado JF, Gomez-Sanchez MA, Saenz de la Calzada C, Sanchez V, Escribano P, Hernandez-Afonso J, et al. Impact of mild pulmonary hypertension on mortality and pulmonary artery pressure profile after heart transplantation. J Heart Lung Transplant. 2001;20:942-8.

9. Deng MC, Gradaus R, Hammel D, Weyand M, Gunther F, Kerber S, et al. Heart transplant candidates at high risk can be identified at the time of initial evaluation. Transpl Int. 1996;9:38-45.

10. Balzer DT, Kort HW, Day RW, Corneli HM, Kovalchin JP, Cannon BC, et al. Inhaled Nitric Oxide as a Preoperative Test (INOP Test I): the INOP Test Study Group. Circulation. 2002;106(12 Suppl 1): I76-81.

11. Zink M, Gombotz H, Wasler A, Grasser B, Rehak P, Metzler H Urapidil reduces elevated pulmonary vascular resistance in patients before heart transplantation. J Heart Lung Transplant. 2002;21: 347-53.

12. Givertz MM, Hare JM, Loh E, Gauthier DF, Colucci WS. Effect of bolus milrinone on hemodynamic variables and pulmonary vascular resistance in patients with severe left ventricular dysfunction: a rapid test for reversibility of pulmonary hypertension. J Am Coll Cardiol. 1996;28:1775-80.

13. Radovancevic B, Vrtovec B, Thomas CD, Croitoru M, Myers TJ, Radovancevic R, et al. Nitric oxide versus prostaglandin E1 for reduction of pulmonary hypertension in heart transplant candidates. J Heart Lung Transplant. 2005;24:690-5.

14. Schulze-Neick I, Luther YC, Ewert P, Lehmkuhl HB, Hetzer R, Lange PE. End-stage heart failure with pulmonary hypertension: levosimendan to evaluate for heart transplantation alone versus combined heartlung transplantation. Transplantation. 2004;78:1237-8.

15. Martin J, Siegenthaler MP, Friesewinkel O, Fader T, van de Loo A, Trummer G, et al. Implantable left ventricular assist device for treatment of pulmonary hypertension in candidates for orthotopic heart transplantation-a preliminary study. Eur J Cardiothorac Surg. 2004; 25:971-7

16. Salzberg SP, Lachat ML, von Harbou K, Zund G, Turina MI. Normalization of high pulmonary vascular resistance with LVAD support in heart transplantation candidates. Eur J Cardiothorac Surg. 2005; 27:222-5.

17. Smedira NG, Massad MG, Navia J, Vargo RL, Patel AN, Cook DJ, et al. Pulmonary hypertension is not a risk factor for RVAD use and death after left ventricular assist system support. ASAIO J. 1996;42: M733-5.

18. Wieselthaler GM, Schima H, Hiesmayr M, Pacher R, Laufer G, Noon GP, et al. First clinical experience with the DeBakey VAD continuousaxial-flow pump for bridge to transplantation. Circulation. 2000;101: 356-9.

19. Pennington DG, McBride LR, Swartz MT. Implantation technique for the Novacor left ventricular assist system. J Thorac Cardiovasc Surg. 1994;108:604-8.

20. Takatani S, Matsuda H, Hanatani A, Nojiri C, Yamazaki K, Motomura T, et al. Mechanical circulatory support devices (MCSD) in Japan: current status and future directions. J Artif Organs. 2005;8:13-27.

21. Anonymous. ACC/AHA guidelines for cardiac catheterization and cardiac catheterization laboratories. American College of Cardiology/ American Heart Association Ad Hoc Task Force on Cardiac Catheterization. J Am Coll Cardiol. 1991;18:1149-82.

22. Butler J, Chomsky DB, Wilson JR. Pulmonary hypertension and exercise intolerance in patients with heart failure. $J$ Am Coll Cardiol. 1999;34:1802-6.

23. Rabinovitch M. Pulmonary hypertension: pathophysiology as a basis for clinical decision making. J Heart Lung Transpl. 1999;18:1041-53. 
24. Todorovich-Hunter L, Dodo H, Ye C, McCready L, Keeley FW, Rabionvitch M. Increased pulmonary artery elastolytic activity in adult rats with monocrotaline induced progressive hypertensive pulmonary vascular disease compared with infant rats with nonprogressive disease. Am Rev Respir Dis. 1992;146:213-23.

25. Turner Gomes SO, Boudreau N, Rabinovitch M. Effect of ambient oxygen changes on platelet activating factor production by fetal ovine endothelial cells. Prostaglandines. 1991;41:463-72.

26. Taghavi S, Zuckermann A, Ankersmit J, Wieselthaler G, Rajek A, Laufer G, et al. Extracorporeal membrane oxygenation is superior to right ventricular assist device for acute right ventricular failure after heart transplantation. Ann Thorac Surg. 2004;78:1644-9.

27. Kirklin JK, Naftel DC, Kirklin JW, Blackstone EH, White-Williams C, Bourge RC. Pulmonary vascular resistance and the risk of heart transplantation. J Heart Transplant. 1988;7:331-6.

28. Kormos RL, Thompson M, Hardesty RL, Griffith BP, Trento A, Uretsky BF, et al. Utility of perioperative right heart catheterization data as a predictor of survival after heart transplantation. J Heart Transplant. 1986;5:391.

29. Erickson KW, Costanzo-Nordin MR, O'Sullivan EJ, Johnson MR, Zucker MJ, Pifarre R, et al. Influence of preoperative transpulmonary gradient on late mortality after orthotopic heart transplantation. J Heart Transplant. 1990;9:526-37.

30. Haddad H, Elabbassi W, Moustafa S, Davies R, Mesana T, Hendry P, et al. Left ventricular assist devices as bridge to heart transplantation in congestive heart failure with pulmonary hypertension. ASAIO J. 2005;51:456-60.

31. Siegenthaler MP, Martin J, van de Loo A, Doenst T, Bothe W, Beyersdorf F. Implantation of the permanent Jarvik-2000 left ventric- ular assist device: a single-center experience. J Am Coll Cardiol. 2002;39:1764-72.

32. Oz MC, Argenziano M, Catanese KA, Gardocki MT, Goldstein DJ, Ashton RC, et al. Bridge experience with long-term implantable left ventricular assist devices. Are they an alternative to transplantation? Circulation. 1997;95:1844-52.

33. International Society for Heart \& Lung Transplantation Registry 2005. Available at: www.ishlt.org. Accessed January 2006.

34. Bleasdale RA, Banner NR, Anyanwu AC, Mitchell AG, Khaghani A, Yacoub MH. Determinants of outcome after heterotopic heart transplantation. J Heart Lung Transplant. 2002;21:867-73.

35. Elefteriades JA, Lovoulos CJ, Tellides G, Goldstein LJ, Rocco EJ, Condos SG, et al. Right ventricle-sparing heart transplant: promising new technique for recipients with pulmonary hypertension. Ann Thorac Surg. 2000;69:1858-63.

36. Akasaka T, Lythall D, Cheng A, Yoshida K, Yoshikawa J, Mitchell A, et al. Continuous aortic regurgitation in severely dysfunctional native hearts after heterotopic cardiac transplantation. Am J Cardiol. 1989; 63:1483-8.

37. Stevenson LW, Rose EA. Left ventricular assist devices: bridges to transplantation, recovery, and destination for whom? Circulation. 2003;108:3059-63.

38. Rose EA, Gelijns AC, Moskowitz AJ, Heitjan DF, Stevenson LW, Dembitsky W, et al; Randomized Evaluation of Mechanical Assistance for the Treatment of Congestive Heart Failure (REMATCH) Study Group. Long-term mechanical left ventricular assistance for end-stage heart failure. N Engl J Med. 2001;345:1435-43.

\section{Online-www.aats.org}

Now you can get The Journal of Thoracic and Cardiovascular Surgery online. The Journal online brings you faster delivery time, easy searching of current and back issues, links to PubMed, AATS, WTSA, and other important sites, and more. Visit the Journal online today.

\section{Receive tables of contents by e-mail}

To receive the tables of contents by e-mail, sign up through our Web site at http://journals.elsevierhealth.com/periodicals/ymtc

Choose E-mail Notification

Simply type your e-mail address in the box and click the Subscribe button.

You will receive an e-mail to confirm that you have been added to the mailing list.

Note that TOC e-mails will be sent out when a new issue is posted to the Web site. 